\title{
O conceito de individualismo metodológico em Hayek revisitado'
}

André Roncaglia de Carvalho*

Resumo: Hayek defendeu, ao longo de sua carreira, o individualismo metodológico como o método mais adequado para as ciências sociais. Sua formulação acerca do individualismo é, todavia, ambígua, oferecendo desafios aos intérpretes de sua obra. O presente artigo busca apresentar uma leitura acerca da constituição do indivíduo hayekiano, baseada na teoria da formação das percepções e no problema do conhecimento, ambos propostos pelo austríaco. Julga-se que a união entre essas duas abordagens permite um entendimento mais claro acerca do conceito de individualismo, tal qual Hayek o concebia. Busca-se, adicionalmente, salientar algumas das limitações enfrentadas pela sua formulação, posicionando-a no pano de fundo das intenções analíticas do autor.

Palavras-chave: Hayek, Individualismo, Regras Sociais.

Abstract: Hayek proposed, all along his career, that the methodological individualism approach is the most adequate method for the social sciences. However, his work on the issue is a source of ambiguities, which offered challenges to the interpreters of his writings. This paper seeks to present an assessment of the constitution of the Hayekian individual, based upon his theory of the formation of perceptions and the problem of knowledge, both proposed by the austrian author. It is argued that the association of these two approaches allows a clearer understanding of the concept of individualism, as Hayek conceived it. In addition, this paper tries to single out some limitations faced by his individualist proposal, fitting it in the background of the analytical intentions of the author.

Keywords: Hayek, Individualism, Social Rules.

JEL Classification: B40; B53.

1 Agradeço ao Prof. João Machado Borges Neto pela atenção que me ofereceu ao longo do desenvolvimento desse artigo. À Profa. Laura V. Mattos e à Profa. Ângela Ganem pelos preciosos comentários e sugestões, sem os quais esse artigo não seria concluído. Por fim, agradeço aos pareceristas anônimos pelas sugestões e correções. Destaco, por fim, que os erros e imprecisões são de minha inteira responsabilidade.

* Mestre em Economia Política pela PUC/SP e Professor do Centro Universitário São Camilo e da Universidade Presbiteriana Mackenzie. 


\section{Introdução}

Friedrich von Hayek desenvolveu estudos que se estendem por uma ampla variedade de assuntos que vão desde a psicologia teórica até a história das idéias, passando pela teoria dos ciclos econômicos e pela teoria evolucionária da herança cultural. Seus escritos deram ensejo a amplas controvérsias, das quais o pano de fundo - ou, se preferirmos, o elemento unificador -, é a defesa do liberalismo econômico como filosofia para a construção de uma sociedade livre e próspera. Apesar de nem sempre ser bem aceito pelas conclusões a que chegou, seu pensamento apresenta uma miríade de questões a serem levadas em conta.

Um dos desafios que Hayek impôs a seus intérpretes refere-se ao significado da expressão "individualismo metodológico". A peculiaridade de sua abordagem pressiona os limites de um esquema classificatório geral, como aquele utilizado por Paulani (2005). Essa dificuldade de classificação é ainda acrescida quando se leva em conta a conotação ambígua que Hayek confere à expressão, como o perceberam adequadamente Burczak (1994, p. 37) e Caldwell (2005). Se, por um lado, o austríaco adverte seus pares, logo no início de sua carreira, quanto à necessidade de dotar a teoria com microfundamentos (HAYEK, [1931] 1935, p. 4), ${ }^{2}$ por outro, Hayek não aceita a teoria social de perfil atomista, reducionista, geralmente denominada de individualismo metodológico. "A solução para esse quebra-cabeça", sugere um comentador, "encontra-se em como a noção de subjetivismo adotada por Hayek implica - por paradoxal que possa parecer - um individualismo metodológico não-reducionista e não-essencialista"3 (BURCZAK, 1994, p. 37).

Hayek (1948c) percebeu, no famoso artigo de 1937 - Economics and knowledge, que o indivíduo neoclássico do modelo de equilíbrio geral não servia como base para a defesa do sistema de mercado, uma vez que essa abordagem ignorava a forma pela qual o conhecimento é adquirido e transmitido. ${ }^{4}$ Ao contrário, no âmbito do embate do

\footnotetext{
2 A abordagem de microfundamentos busca explicar os resultados econômicos - no caso do início da carreira de Hayek, os ciclos econômicos - em termos de iniciativas individuais (em oposição à dedução da ação individual a partir de uma suposta apreensão de estruturas sociais autônomas).

3 "I understand an essentialist social theory to be one that conceives social outcomes to be reducible to some pregiven causal agents(s)" (BURCZAK, 1994, p. 31).

4 Nas palavras de Hayek: "my main contention will be that the tautologies, of which formal equilibrium analysis in economics essentially consists, can be turned into propositions which tell us anything about causation in the real world only in so far as we are able to fill those formal propositions with definite statements about how knowledge is acquired and communicated" (HAYEK, 1948c, p. 33).
} 
cálculo socialista, a teoria neoclássica tendia a favorecer o argumento de seus adversários socialistas. O austríaco abandona, então, seus estudos específicos em teoria econômica e passa a desenvolver um programa de pesquisa sobre a formação e evolução das instituições. ${ }^{5}$

Este artigo apresenta uma leitura do individualismo metodológico, tal como entendido por Hayek. Entende-se que um aspecto do quadro analítico de Hayek é crucial para uma leitura adequada de sua obra: o caráter privado e único da individualidade humana. Tal unicidade deriva de uma metodologia específica de análise dos processos sociais. Hayek evita delinear uma determinação do indivíduo pela estrutura social, ${ }^{6}$ optando pela constituição da individualidade a partir de sua apreensão da coletividade. Tal expediente, como se buscará mostrar, promove uma tentativa de apresentar uma constituição do indivíduo em moldes evolucionários. Para fundamentar essa posição é preciso investigar como a constituição social da individualidade não invalida o papel do indivíduo como agente-motor do processo social.

$\mathrm{O}$ artigo divide-se em cinco partes, além dessa introdução. A segunda seção discorre sobre as principais abordagens do método individualista no contexto da relação indivíduo-sociedade. Em seguida, na terceira parte, passa-se a uma apresentação da problemática enfrentada pela teoria hayekiana, ao postular um individualismo fortemente influenciado por instituições e regras sociais. A quarta seção tenta fazer uma releitura lógica da composição do indivíduo hayekiano com base na combinação entre o processo de formação das percepções e a questão do conhecimento. Essa união de conceitos dará ensejo à conceituação do "verdadeiro" individualismo, objeto da quinta parte desse trabalho. Por fim, a sexta seção ressalta as principais dificuldades de interpretação apresentadas pelo conceito hayekiano de individualismo metodológico.

5 Além de Paulani (2005), há outras interpretações sobre a "transformação de Hayek". Cada uma delas aponta aspectos diversos da continuidade ou descontinuidade no pensamento do austríaco, desde aspectos metodológicos, como a influência de Popper sobre Hayek incentivando-o na direção do falsificacionismo (HUTCHINSON, 1981), passando pela sua experiência em teoria monetária de tradição wickselliana (SOROMENHO, 1994), assim como a sua participação no debate sobre a possibilidade do cálculo econômico no socialismo de (CALDWELL, 1988; 2005), até a perfeita coerência e unidade de toda a sua carreira intelectual (BIRNER e ZIJP, 1994), por vezes vista como decorrência de seu interesse pelo problema de coordenação (O’DRISCOLL, 1977).

6 Para Marx, "não é a consciência do homem que determina sua existência, mas, pelo contrário, a sua existência social que determina a sua consciência" (MARX, Prefácio à Crítica da Economia Política de 1859 apud GALIPOLO; GALA; FERNANDES, 2005, p. 15). 


\section{A relação indivíduo-sociedade e os conceitos formais de "individualismo"}

A relação de causalidade entre indivíduo e sociedade constitui um aspecto demarcatório de escolas de pensamento na área das humanidades. A questão fundamental se coloca, em termos genéricos, da seguinte forma: é o indivíduo que determina a sociedade, ou seria o indivíduo mero produto do meio? Mas, ainda assim, quem produziria o meio? Não é preciso muito esforço para perceber que se trata de um problema $a b$ ovo, para o qual a introspecção humana se vê desprovida de ferramentas científicas para sua devida (e objetiva) verificação. Isso se deve ao fato de que essa determinação é fundamentalmente um fenômeno abstrato: não há, nos fósseis de antigas civilizações, um registro sistemático e documental das relações indivíduo-sociedade.

Deste modo, para evitar o retorno dogmático e inútil às origens da humanidade, constroem-se esquemas explicativos para tentar captar os efeitos dessas relações sobre a organização da sociedade. Parte-se de um ponto específico, arbitrariamente selecionado pelo cientista social. Esse ponto de entrada pode ser, por exemplo, o indivíduo provido de diferentes graus de autonomia decisória (individualista), ou o "todo" social dotado de autonomia funcional (coletivista). No primeiro, o "todo" social seria uma resultante das inúmeras decisões individuais, ao passo em que, no segundo, o indivíduo seria em grande medida determinado pelos processos sociais globais. É sobre o primeiro que se debruça o presente artigo.

Podem-se agrupar os diversos conceitos de individualismo em duas categorias fundamentais: o individualismo ontológico e o individualismo metodológico. No primeiro, o indivíduo é marcado pelo autocentramento e pela autodeterminação, constituindo o elemento basilar da versão neoclássica do equilíbrio competitivo individualista de Adam Smith. Só o indivíduo age. Suas escolhas não são afetadas por externalidades, isto é, todo o benefício oriundo das transações é absorvido de forma privada. As relações entre os indivíduos se dão de forma imediata no mercado, isto é, não são mediadas por instituições ou grupos sociais ou outras instâncias supra-individuais. Por trás desse constructo está a idéia de que a interação social entre os indivíduos não adiciona nada de novo ao resultado simples e direto da soma das partes. Para que ela funcione adequadamente é preciso que o processo se submeta ao governo da "mão invisível". ${ }^{7}$

$7 \mathrm{Ou}$, ainda, como é mais característico desse modelo, ao leiloeiro walrasiano (SCREPANTI; ZAMAGNI, 2005, p. 390-391). 
Já no contexto do individualismo metodológico, o indivíduo é o ator-sujeito da sociedade e dos processos que nela se desenrolam. O indivíduo é influenciado sobremaneira pelo funcionamento do grupo, ao mesmo tempo em que contribui para a formação do mesmo. Ficaria indeterminado, portanto, o sentido de influência entre indivíduo e sociedade. Segundo essa abordagem, toda explicação acerca de fenômenos sociais deve partir, compulsoriamente, da análise das ações dos indivíduos que compõem determinado grupo social. Trata-se, efetivamente, de uma postura intelectual, uma abordagem metodológica, frente à complexidade dos problemas gerados pela interação social dos agentes.

Como qualquer teoria, há algum grau de abstração envolvido em suas inquirições. Assim sendo, o problema fundamental enfrentado pelos individualistas metodológicos pode ser postulado da seguinte maneira. Por um lado, a sociedade é constituída pelas manifestações espontâneas das faculdades humanas (particulares a indivíduos vivendo em grupo), isto é, a relação entre os componentes de uma coletividade e os resultados produzidos pela interação de seus membros desenha uma relação de causalidade do tipo "indivíduo $\rightarrow$ sociedade". Por outro lado, no sentido contrário, tem-se que o indivíduo é influenciado pela consolidação histórica de processos sociais na forma de costumes e leis, ou seja, inverte-se a relação para uma do tipo "sociedade $\rightarrow$ indivíduo". Dessa forma, coloca-se o seguinte problema: como emplacar a figura do indivíduo como agente-motor do processo social, visto que ele é, ao mesmo tempo, influenciado pelo mesmo processo de que ele é o móvel?

A explicação dessa relação se divide em dois momentos: a metateoria e a teoria. A metateoria pode ser descrita como o "entry point", 8 isto é, o ponto de partida a partir do qual se dá o anúncio de suas intenções analíticas, isto é, a base do discurso (por exemplo, só o indivíduo decide e age). A teoria se ocupa da esquematização do argumento em categorias analíticas logicamente inter-relacionadas (seguindo o exemplo, a sociedade resulta das decisões e ações dos indivíduos que a compõem). Dessa forma, ao adotar-se uma metateoria, deve-se manter a coerência analítica quando da passagem para a formulação do esquema explicativo. Em uma palavra, trata-se de impedir que o discurso se choque com a prescrição teórica.

8 A expressão é de Burczak (1994, p. 51).

Carvalho, A. R. O conceito de individualismo metodológico em Hayek revisitado 


\section{Conhecimento, regras sociais e individualismo metodológico}

Em Economics and Knowledge, Hayek (1948c) coloca em evidência o conhecimento que os economistas consideram "dados" para os agentes econômicos, e conclui que, em realidade, esse conhecimento não existe. Para o austríaco, o saber não é objetivo, mas, sim, subjetivo e está atrelado à atividade produtiva de cada um; todavia, estende-se para além do conhecimento dos preços correntes ou das expectativas em relação aos preços futuros. Trata-se de um saber associado a tempo e espaço.

The wider aspect of the problem of knowledge with which I am concerned is the knowledge of the basic fact of how the different commodities can be obtained and used, and under what conditions they are actually obtained and used, that is the general question of why the subjective data of different persons correspond to the objective facts (HAYEK, 1948c, p. 50-51).

Portanto, se o conhecimento objetivo não existe e o que realmente determina as percepções do agente é a sua particular subjetividade frente ao mundo externo, tem-se que cada indivíduo é um elemento único. Assim, um traço fundamental da teoria hayekiana é a impossibilidade do conhecimento objetivo, peça basilar de um arcabouço subjetivista radical. Para o austríaco, portanto, toda a análise das questões sociais deve passar, necessariamente, pela compreensão dos hábitos de pensamento dos indivíduos que constituem determinada coletividade (HAYEK, 1979, p. 64). Todavia, em oposição à subjetividade fundada sobre princípios universais da razão, como o queria Kant, Hayek acredita que tais princípios são erigidos individualmente, a partir das experiências específicas de cada ser humano. Trata-se, portanto, de uma subjetividade constituída por inúmeros aspectos da vida social. Todavia, deve-se perguntar: como se forma tal subjetividade?

Burczak (1994, p. 41-44) faz um inventário dos elementos constituintes da individualidade subjetiva hayekiana. Baseando-se em diversos textos de Hayek, o autor esquematiza a constituição da percepção individual a partir de quatro elementos. O primeiro é a linguagem e o discurso: a linguagem é uma ordem espontânea, isto é, um estado de coisas que é um resultado não intencional de ações individuais autointeressadas; em outras palavras, por meio dela se adquire, sem se dar conta disso, um arcabouço para ordenar e contextualizar as percepções formadas (um discurso ou uma teoria) a partir dos estímulos oriundos do mundo externo. 
O segundo é a localização: conjunto de "circunstâncias específicas de espaço e tempo" que torna cada indivíduo uma "singularidade irredutível", sendo este detentor de uma "especialização" que lhe confere posse de informações que ele detém com exclusividade, isto é, não se trata de conhecimento transferível a outras pessoas. $\mathrm{O}$ terceiro fator é formado pelo tempo e pelas expectativas: as ações de um indivíduo devem estar em equilíbrio entre si. Como as ações se dão ao longo do tempo, a ação humana se liga às percepções de possibilidades futuras, ou seja, as expectativas.

Por fim, o quarto elemento é o conjunto de regras sociais. Essas influenciam a percepção do indivíduo em relação ao mundo e às ações dos outros indivíduos. Ademais, elas servem como proteção contra a alteridade do futuro, proporcionando ao indivíduo um parâmetro pelo qual referenciar suas ações. É interessante notar, contudo, que as regras não resultam de um contrato deliberado de indivíduos autocentrados, não podendo ser reduzidas às ações de indivíduos racionais. ${ }^{9}$ Elas emergem como subproduto de um processo de imitação e identificação, o qual não depende da capacidade humana em descrevê-lo racionalmente. ${ }^{10}$

$\mathrm{O}$ autor assinala que, para Hayek, a indeterminação do futuro impõe aos indivíduos a convivência compulsória com a incerteza, levando-os a fazer escolhas cujas restrições são desconhecidas e cujos resultados são imaginados. Essa ignorância irremediável conduz à formulação de instituições, convenções e regras como guias à ação, quando as conseqüências desta são desconhecidas. Todavia, a utilização dessas regras é, em grande medida, uma adesão tácita, de forma que "as pessoas podem 'saber como' desempenhar uma determinada ação sem 'saber que' - isto é, serem capazes de articular [racionalmente] - suas ações seguem uma determinada regra" (BURCZAK,

9 "A ênfase de Hayek nesse caráter das regras e convenções como essencialmente não redutíveis ao saber racional deve-se ao fato de que, como nosso conhecimento é limitado, nós, cada um de nós realmente ignora a maior parte dos fatos que determinam os processos da sociedade. (Daí que não pode ser possível querer demonstrar a ordem de mercado através de uma antecipação racional de seus resultados). Por isso, as regras, em sua maior parte, são seguidas sem ser postuladas" (PAULANI, 2005, p. 104).

10 "Rule-guided perception is important for Hayek because it indicates the limits to reason as the regulatory mechanism of mental processes: The rules guiding individual perception, as in the case of the child's understanding of a smile, often are not understood and cannot be described" (BURCZAK, 1994, p. 44). Sobre o sorriso da criança, o autor qualifica: "For example, a child can understand a smile and return the expression without being able to articulate the meaning of the smile. The child's understanding of the smile is an example of rule-guided perception" (BURCZAK, 1994, p. 41). 
1994, p. 45). Hayek conclui, assim, sua defesa das graves limitações da razão humana, relegando a regras impessoais a tarefa de manutenção de uma sociedade livre. Em suma, os processos sociais não podem ser planejados racionalmente (daí sua oposição ao termo organização), mas são, sim, disciplinados pela emergência de propriedades sociais resultantes da interação de particularidades individuais no espaço de existência social.

As regras hayekianas emergem nesse quadro de ignorância e sabedoria, incerteza e seleção e são elas que dão substractum a ordem espontânea, natural do mercado. Essa ordem catalítica como Hayek a define, emana da práxis, da experimentação e não de um arranjo operado por alguém. Como não é construída, não pode ser reconstruída mentalmente caracterizandose por ser uma estrutura transcendental, uma categoria inacessivel à razão que expressa uma multiplicidade de fins distintos e incomensuráveis de todos os seus membros individuais (GANEM, 2005, p. 9).

A manifestação da individualidade se dá, com efeito, em três dimensões: os propósitos particulares de cada ser humano, seu conhecimento subjetivo e as regras sociais (as quais constituem seu comportamento em intensidade variável, e de acordo com a situação e com o indivíduo). Tais dimensões se inter-relacionam constantemente no contexto da existência social do indivíduo. Tal "espaço" social impõe ao indivíduo a adesão tácita à utilização de instrumentos de interação social, além de algumas limitações de caráter físico ou cognitivo. As percepções subjetivas, expoentes máximos da singularidade intransponível de cada agente econômico, são, em essência, fortemente influenciadas pelas instituições sociais. Assim, carece de precisão dizer que a percepção é determinada pos instâncias supra-individuais; ela é, antes, "constituída, isto é, não é determinada por nada em particular e ao mesmo tempo é afetada por infinitas coisas, nenhuma das quais é a essencial" (BURCZAK, 1994, p. 41).

Paulani (2005, capítulo 4) indica haver uma tensão entre a metateoria de Hayek e sua prescrição teórica, representando um certo "desconforto" conceitual enfrentado pelo austríaco. Sua metateoria postula que o indivíduo é o veículo da ação social, enquanto a teoria busca construir uma explicação sobre os fenômenos sociais a partir desse elemento basal adotado. Nesse sentido, o modelo representativo da organização da sociedade deve mostrar como a ação descentralizada de indivíduos e, por isso, livres de qualquer influência externa (determinante) dão origem à ordem social que lhes é superior, mas que é, também, resultado não intencional de suas iniciativas 
auto-interessadas. Seria nessa articulação da teoria, a partir da metateoria, que Hayek teria desnudado a natureza contraditória da figura do "indivíduo" da sociedade capitalista.

A tensão se revelaria quando o discurso que postula a soberania do indivíduo se desfaz, desnudando uma existência social que depende de regras que ele segue sem compreendê-las racionalmente. $\mathrm{O}$ argumento da autora segue a seguinte lógica. Partindo-se da idéia de que o indivíduo é soberano em suas decisões, deve-se entender que suas ações estão livres da influência de quaisquer instâncias superiores ao seu livre-arbítrio. Assim, seu comportamento não é determinado por nada que seja alheio à constituição de sua escala de valores e da hierarquia de suas preferências (PAULANI, 2005, p. 93). Se a soberania individual é incorruptível, como explicar que o suposto benefício causado à instância que lhe é diretamente superior realimenta o seu comportamento? Se nada o influencia, como se explica a realimentação? Se nada determina o seu comportamento, de onde vêm as suas preferências? A única saída possível é adotar-se a estática comparativa, isto é, truncar o processo analítico e assumir que, a cada decisão, o feedback loop é um "dado" inicial do modelo.

Esse parece ser o expediente adotado pela teoria neoclássica, mas, será ele atribuível a Hayek? A autora reconhece que não. Ao contrário, Hayek se ampara na existência de regras sociais que emergem da interação dos indivíduos vivendo em sociedade e das quais eles não têm plena consciência. A autora conclui, portanto, que, ao tentar fugir à contradição lógica representada pelo individualismo metodológico do modelo de equilíbrio geral, Hayek "abre, por isso mesmo, um espaço privilegiado para que o objeto se revele como contradição" (PAULANI, 2005, p. 109).

Paulani (2005, p. 106) conclui que Hayek patrocina, de forma nítida e irrefutável, o "esboroamento" da "autodeterminação" do indivíduo e sua diluição completa na coletividade. Dada a indeterminação dos fatores que lhe constituem a subjetividade, o sujeitoator fica perdido, sem origem e, principalmente, sem a sua tão aclamada soberania. $\mathrm{O}$ verdadeiro individualismo professado por Hayek seria, na visão da autora, aquele em que a sociedade é composta por agentes interdependentes, cujas percepções subjetivamente retidas sobre os eventos do mundo externo e a respeito das ações dos seus pares são constituídas por circunsstâncias de espaço e tempo, pela linguagem e pelas regras sociais vigentes. Essas duas últimas categorias resultam de processos sociais espontâneos, cuja decomposição em termos das ações individuais não é possível de se obter. Hayek 
deixaria exposta, assim, a contradição que caracteriza seu ator-sujeito: sua soberania inviolável (metateoria) é determinada socialmente (teoria). Nas palavras da autora:

Os pressupostos que efetivamente constituem o indivíduo enquanto indivíduo (igualdade jurídica, liberdade, propriedade privada) negam o seu operar enquanto sujeito, porque solapam sua suposta autonomia. Que sujeito é esse que, sem o saber (ou eventualmente até sabendo, mas sem ter o que fazer), produz resultados a que não visa, não deseja, dos quais nem sempre gosta? Assim, a verdadeira posição do indivíduo, sua posição positiva, implicaria a recuperação dessa autonomia, ou seja, de um fazer que fosse só intencional. Mas, fora do "Bureau Planejador", que ao fim e ao cabo mata o mesmo indivíduo, onde buscar tal realização? (PAULANI, 2005, p. 108).

O que está em foco, esclarece a autora, é em que medida o "verdadeiro individualista" conhece o objeto que defende: o indivíduo. A pergunta principal a se colocar é a seguinte: em que medida pode-se garantir que a metateoria de Hayek adota a figura do indivíduo como "algo autodeterminado"? ${ }^{11}$ Uma vez respondida essa pergunta, será possível reavaliar se a teoria desenvolvida pelo autor austríaco de fato anula o status do indivíduo no processo social. E, se não o anula, de que forma a redução do grau de "soberania" implica um abalo ao status social do indivíduo.

\section{A constituição do indivíduo hayekiano}

A trajetória intelectual de Hayek é objeto de diversos estudos. Não é um exagero dizer que durante grande parte de sua carreira, Hayek esforçou-se para fundamentar cientificamente a filosofia liberal. Entretanto, sua tentativa se dava em consonância com o flagrante sucesso econômico da União Soviética no pós-primeira guerra. Caldwell (2005, p. 216) endossa a tese de que o debate do cálculo socialista tenha servido como um catalisador no desenvolvimento e articulação da visão moderna da escola austríaca, que vê o mercado como um processo de descoberta competitivo-empresarial. As origens dessa concepção remetem ao famoso artigo de 1937.

Em Economics and Knowledge, Hayek (1948c) coloca em xeque a validade do modelo de equilíbrio geral. Como defeito principal, esse modelo impõe ao indivíduo o esvaziamento das capacidades individuais e, portanto, elimina o espaço para a adoção de propósitos particulares. Ao sistematizar o conhecimento como um bem público, isto

11 A expressão se encontra em Paulani (2005, p. 101). 
é, não-exclusivo e não-rival, o modelo ignorava uma característica essencial da sociedade capitalista: os espaços privados; ${ }^{12}$ esses resultam de atributos biológicos, espaciais, psicológicos e sociais da condição humana. Biologicamente, um ser humano é um corpo único e, portanto, indivisível. Disso resulta a exclusividade de sua localização espacial. Essa localização intransferível constitui relevante fonte de estímulos para a sua mente, cuja experiência sensória é vertida no espaço físico na forma de um conjunto de ações. Ao passar para um espaço social, agrega-se ao espaço antes fisicamente determinado, uma dimensão abstrata formada pelo conjunto de ações de duplo efeito. Essa duplicidade se deve à natureza bidimensional da esfera em que se manifestam essas ações. Formam-se, portanto, um território interespacial e um território interpessoal, ambos detendo porções de influência recíproca. $\mathrm{O}$ indivíduo detém sua peculiaridade não pela sua autonomia completa em relação a tudo e todos, isto é, ao seu autogoverno independente de qualquer força externa. Ele é indivíduo, sim, pelas ilimitadas possibilidades de combinação entre essas duas dimensões que compõem sua condição de ser humano. $\mathrm{O}$ indivíduo só o é como parte de um todo. Caso contrário não faria sentido o esforço analítico de redução à menor parte constitutiva de um determinado corpo.

Os individualistas parecem querer escapar à noção de que haveria um canal direto, singular e homogêneo entre a individualidade bidimensional do ser humano e o todo que ele ajuda a construir. A realidade objetiva é captada de maneira indireta, isto é, as percepções individuais são formadas após uma série de "filtros" em diferentes níveis. Trata-se de um "realismo indireto" (FESER, 1999). Hayek partilha dessa concepção.

Hayek ([1952] 1967) investiga, em estudo sobre psicologia teórica, intitulado The Sensory Order, os determinantes da relação mentecorpo. De maneira sucinta, haveria dois tipos de ordem: a ordem física e a ordem sensorial. A primeira é sistematizada pelas ciências naturais por meio de seu método classificatório, ao passo em que a segunda consiste nas experiências dos seres humanos. A evidência que comprova essas duas ordens pode ser provada pelas reações a certos

12 À época em que escreveu esse artigo, Hayek se dedicava a uma revisão da obra de Menger (CALDWELL, 1988, p. 533, n. 19) de forma que o método analítico-compositivo do fundador da escola austríaca pode ter influenciado significativamente os desenvolvimentos subseqüentes do primeiro. O método compositivo consiste em partir das partes mais fundamentais que compõem um problema e, gradativamente, adicionar os resultados das interações entre as partes até que o fenômeno observado seja explicado. No caso dos austríacos, significa adotar como ponto de partida as decisões dos indivíduos construindo, passo a passo, a dinâmica social. Não se trata de demonstrar a autodeterminação de suas motivações, como parece sugerir Paulani (2005, p. 108), mas de adotá-las como ponto de partida. 
estímulos. Por exemplo, instrumentos científicos revelam uma variedade de cores muito maior do que o olho humano pode captar. Assim, não se pode distinguir entre sal, cocaína, anthrax ou aspirina moída simplesmente olhando para ela. Com efeito, Hayek mostra que tendemos a classificar como similares objetos e sensações que, na ordem física tem pouca relação entre si.

\begin{abstract}
What we call 'mind' is thus a particular order of a set of events taking place in some organism and in some manner related to but not identical with, the physical order of events in the environment. The problem which the existence of mental phenomena raises is therefore how in a part of the physical order (namely an organism) a sub-system can be formed which in some sense (yet to be more fully defined) may be said to reflect some features of the physical order as a whole, and which thereby enables the organism which contains such a partial reproduction of the environmental order to behave appropriately towards its surroundings. The problem arises as much from the fact that the order of this sub-system is in some respects similar to, as from the fact that it is in other respects different from the corresponding more comprehensive physical order (HAYEK, [1952] 1967, p. 16).
\end{abstract}

A realidade objetiva existe, mas nunca é apreendida de maneira direta. O sistema nervoso central recebe os estímulos provenientes da ordem física e seguindo um processo de crescentes níveis (higher centers) de classificação transforma-os naquilo que os seres humanos experimentam. Essa classificação está condicionada pela organização fisiológica, isto é, pela disposição específica de cada neurônio no sistema nervoso. Um evento pode ser tratado como membro de uma categoria de classificação e pertencer a outra quando seu estímulo correspondente for combinado com outros eventos. O resultado da experiência e o aprendizado é a formação de um sistema de conexões, pelo qual um estímulo pode ser transmitido de neurônio para neurônio (HAYEK, [1952] 1967, p. 53). Mais adiante, Hayek distingue as sensações das percepções, dizendo ambas fazerem parte de diferentes estágios desse mesmo processo de classificação de estímulos desempenhado pelo sistema nervoso (HAYEK, [1952] 1967, p. 78).

Como vimos, a variedade de relações que se forma na ordem sensorial é ilimitada. Adicionalmente, a formação dessa rede é um processo contínuo. A ordem mental que resulta é uma aproximação da ordem física, a qual transmitida por meio de estímulos; esses geram impulsos, que "representam" a ordem física. Assim, a mente se parece com um mapa da ordem física. Representa-o, mas de maneira modelar, incompleta: reproduz as relações entre classes de eventos que ocorrem no ambiente.

Mas não é só isso, cada organismo formará uma rede distinta, uma vez que a sensibilidade dos órgãos receptores a diferentes estímulos 
é desenvolvida por forças evolucionárias, de forma que o ambiente em que um organismo habita afetará os tipos de estímulos que ele vai encontrar. Além disso, o ambiente interno do organismo, isto é, a constituição de seu sistema nervoso influenciará a formação das redes, de forma que a capacidade de classificação em nível elevado de complexidade não é uniformemente distribuída entre os indivíduos (CALDWELL, 2005, p. 268). É nesse ponto que Hayek é categórico em afirmar que:

The different maps which will thus be formed in different brains will be determined by factors which are sufficiently similar to make those maps also similar to each other. But they will not be identical. Complete identity of the maps would presuppose not only an identical history of the different individuals but also complete identity of their anatomical structure. The mere fact that for each individual the map will be subject to constant changes practically precludes the possibility that at any moment the maps of two individuals should be completely identical (HAYEK, [1952] 1967, p. 110 grifos do autor).

Assim como não há dois flocos de neve iguais, nenhum ser humano é igual a outro. ${ }^{13}$ Dessa forma, deve-se considerar a dimensão sensória da individualidade do ser humano. Como cada percepção é resultado de uma classificação, tem-se que essa decorre de uma "interpretação" da realidade baseada na experiência do indivíduo (HAYEK, [1952] 1967, p. 42). O conhecimento que um indivíduo detém, portanto, não é mais do que uma interpretação parcial e imperfeita de uma realidade mais complexa do que sua mente pode compreender. ${ }^{14}$ As implicações econômicas da teoria hayekiana da mente são assinaladas por Caldwell (2005):

13 A comparação é de Caldwell (2005, p. 268): "Like snowflakes, no two people are alike. The maps that our minds create are subject to gradual change. A map is formed by past impulses, but it is relatively permanent vis-à-vis the particular impulses that may be proceeding through it at a given point in time. It provides the structure by which any new impulses are categorized and determines which subsequent classes of impulses are created. The sequence of impulses over time will affect the structure (...)"

14 Hayek escreveu esse tratado em oposição à tradição behaviorista da psicologia.Essa linha estuda as relações observáveis entre estímulos e respostas. Alguns de seus representantes imaginavam poder fornecer um conjunto de ferramentas para a construção de uma nova sociedade, uma vez que as técnicas de "condicionamento" ofereciam meios para alterar o comportamento humano indisciplinado, para tornar os trabalhadores mais eficientes e, por fim, para formatar uma série de atividades humanas de acordo com parâmetros mais aceitáveis. A crítica que Hayek dirigia a essa escola consistia em assinalar a desconsideração da subjetividade das experiências mentais: um único estímulo poderia gerar diferentes séries de respostas, em seqüências distintas. A tentativa behaviorista de eliminar da ciência o papel da interpretação é consistentemente questionada pela teoria da ordem sensorial, a qual defende que processos de seleção, avaliação e interpretação ocorrem em cada etapa da criação da ordem mental (CALDWELL, 2005, p. 270-271). 
[...] quite clearly, his explanation of the principles by which the mind forms is fully consistent with his bedrock claim in economics that knowledge is dispersed and belief is subjectively held. Even if two individuals existed in the same environment, the mental maps that they formed would be somewhat different, and their knowledge and beliefs would, therefore, differ as well (CALDWELL, 2005, p. 277).

Por essas razões, Hayek era cético em relação a estudar o processo de formação das preferências, dado o grau de complexidade da questão. $\mathrm{O}$ indivíduo mesmo seria incapaz de compreender a origem de suas preferências, uma vez que a mente não consegue compreender a si própria, mas somente algo cuja estrutura é menos complexa do que a dela. É no livre uso de suas faculdades que o indivíduo passa a ampliar o conhecimento que tem acerca de suas preferências. Impedi-lo de aplicar tais capacidades era, para Hayek, a maior ofensa à liberdade individual. Pode ser que o bem-estar material de uma sociedade planejada até atingisse níveis elevados, mas ele entendia que a genialidade humana teria de ser condicionada a limites estreitos da condição de equilíbrio geral do sistema econômico. Enfim, teria de adotar como seu fim o objetivo de outra pessoa.

\section{0 individualismo hayekiano}

Ao discorrer sobre o conceito de individualismo, Hayek ([1946] 1948b) busca diferenciar dois métodos distintos que utilizam a mesma denominação. Existem dois individualismos: o verdadeiro e o falso. Esse último descende da filosofia racionalista dos pensadores do iluminismo francês do século XVIII, cujo principal representante é René Descartes. Segundo essa tradição, a sociedade poderia ser organizada pela razão humana com " $\mathrm{R}$ " maiúscula, uma vez que a racionalidade estava completa e igualmente disponível a todos os seres humanos. Adicionalmente, alegava que tudo o que o homem construía era resultado direto da razão individual e, por isso, sujeito ao controle da mesma. Uma espécie de engenharia politécnica da sociedade (HAYEK, [1946] 1948b, p. 8).

Por outro lado, o verdadeiro individualismo era pregado pelos pensadores iluministas escoceses do século XVIII como Adam Smith, Josiah Tucker, Adam Ferguson e Edmund Burke. Essa tradição atribuía a organização da sociedade aos efeitos não pretendidos das ações de indivíduos buscando seus próprios objetivos. A sociedade seria composta não por pessoas de ilimitado poder lógico-dedutivo, mas por 
indivíduos largamente "irracionais" 15 e falíveis, cujos erros são corrigidos no curso do processo social. O ser humano seria um "material imperfeito" cujas atividades fazem pouco uso da razão, sendo essa limitada e imperfeita. ${ }^{16}$

O individualismo cartesiano explicava a formação da sociedade como a união das vontades individuais conciliadas por um contrato formal, ou seja, a abordagem do contrato social de Rousseau. Esse tipo de individualismo deixava implícito que os processos sociais somente poderiam atender aos fins humanos caso estivessem sob o controle da razão humana, o que implicava um salto direto para o socialismo. Controle da razão humana implica controle dos fins das ações individuais; ou, ainda, um processo de coordenação centralmente conduzido pela vontade deliberada do ser humano. Mas, de quais seres humanos? Todos aqueles que compõem a sociedade? Ou somente dos líderes políticos?

Hayek definia o seu individualismo em oposição à possibilidade de uma definição estrita e objetiva dos fins gerais dos indivíduos por parte de um governo central falível e com forte propensão ao abuso do poder de violência. A centralidade da organização racional da sociedade gerava espaços potenciais para desfrute de privilégios, de uma distribuição desigual do poder político. Dever-se-ia reduzir ao máximo as oportunidades de os indivíduos perpetrarem o mal à sociedade; em outros termos, o objetivo deve ser "um sistema em que os homens maus podem cometer menos danos" (HAYEK, [1946] 1948 b, p. 11). Mas porque homens maus? O perfil do "homem" analisado pelos iluministas escoceses era, em verdade, um ser humano

15 Nos termos do autor, o pensamento anti-racionalista dos iluministas escoceses "regards man not as a highly rational and intelligent but as a very irrational and fallible being, whose individual errors are corrected only in the course of a social process, and which aims at making the best of a very imperfect material" (HAYEK, [1946] 1948b, p. 8 - grifos nossos). O termo "irracional" pode ser entendido aqui não como ausência de racionalidade, na estrita acepção do conceito. Apoiando-se em Mises, é possível dizer que, no plano da ação humana, o oposto de racionalidade é a "ação inconsciente", isto é, a ação desprovida de um propósito (FEIJÓ, 2000, p. 107). Em outras palavras, Hayek está frisando o ceticismo dos autores iluministas no que se refere ao poder da racionalidade humana frente ao processo social que inapelavelmente lhe envolve em seu bojo.

16 Nas palavras do autor: "One might even say that the former [verdadeiro individualismo escocês] is a product of an acute consciousness of the limitations of the individual mind which induces an attitude of humility toward the impersonal and anonymous social processes by which individuals help to create things greater than they know, while the latter [falso individualismo cartesiano] is the product of an exaggerated belief in the powers of individual reason and of a consequent contempt for anything which has not been consciously designed by it or is not fully intelligible to it" (HAYEK, [1946] 1948b, p. 8). 
naturalmente preguiçoso, indolente, imprevidente e perdulário, de forma que somente a força das circunstâncias poderia fazê-los se comportar de forma econômica, isto é, ajustar seus meios a seus fins. Daí a preocupação, que Hayek revalida, de se procurar um conjunto de instituições que induzissem os indivíduos a contribuir tanto quanto possível para atender às necessidades dos outros. Não se tratava de coagi-los pela força, mas de incentivá-los por meio dos propósitos e escolhas que determinavam sua conduta. Essa estrutura de incentivos recebia o nome de propriedade privada. ${ }^{17}$

A propriedade privada alberga o auto-interesse, potenciando-o e protegendo-o. Este último é um resultado de sua limitação cognitiva em relação ao processo social como um todo; trata-se de uma necessidade lógica, na compreensão do austríaco. Como decorrência disso, o homem não pode inserir em suas motivações mais do que os efeitos imediatos de suas ações na esfera que ele conhece. Mesmo sendo uma pessoa dotada de forte altruísmo, as necessidades humanas às quais ele pode efetivamente atender conformam uma fração pouco expressiva do conjunto das necessidades de todos os membros da sociedade. Logo, a verdadeira questão não reside na natureza de sua motivação (se egoísta ou altruísta), mas em transformar os efeitos desse propósito íntimo em indutores efetivos para sua contribuição voluntária com as necessidades que lhe escapam ao campo de entendimento. O mercado satisfaz essa carência de visão global, isto é, por meio dele os indivíduos auxiliam, sem saber, a obtenção de fins que não faziam parte de suas pretensões.

Ao deixar os homens perseguirem seus fins particulares, suas capacitações e habilidades são colocadas em prática de maneira mais eficaz. A concepção subjacente a essa proposta é a de que, dada a ilimitada variedade de habilidades e dons humanos e, uma vez que o conhecimento subjetivo é, em grande medida, determinado pela aplicação dessas habilidades, nenhuma pessoa pode sozinha deter todo o conhecimento derivado das atividades de todos os outros membros da sociedade. Logo, a razão não é única, mas multifacetada, devendo

17 "They did not contend, however, that this system was incapable of further improvement and, still less, as another current distortion of their arguments will have it, that there existed a "natural harmony of interests" irrespective of the positive institutions. They were more than merely aware of the conflicts of individual interests and stressed the necessity of 'wellconstructed institutions' where the 'rules and principles of contending interests and compromised advantages' would reconcile conflicting interests without giving any one group power to make their views and interests always prevail over those of all others" (HAYEK, [1946] 1948b, p. 13). 
ser vista como um processo interpessoal ao longo do qual a contribuição de um é testada e corrigida pela participação do outro. ${ }^{18}$

Em suma, trata-se, efetivamente, de permitir que cada indivíduo persiga seus próprios fins. Não se discute aqui a formação das vontades e das preferências dos indivíduos, ${ }^{19}$ uma vez que a decomposição desse processo torna-se por demais complexa. Exige-se, dessa feita, que tais vontades e referências sejam tomadas como dadas. Mas, então, como fica o indivíduo? Onde se encontra a unicidade do ser humano vivendo em sociedade? Tem-se, assim, uma demonstração da ambigüidade na definição da metateoria de Hayek, haja vista que ele não atribui ao indivíduo uma autodeterminação soberana. Ao contrário, trata-se de um indivíduo cujo caráter e cuja natureza são completamente determinados pela sua existência em sociedade. $\mathrm{O}$ que o autor propõe é um entendimento da realidade social como sendo resultado de ações individuais direcionadas a outras pessoas. Mais que isso, entende-se que tais ações são guiadas pelo comportamento esperado de seus semelhantes (HAYEK, [1946] 1948b, p. 6).

Há, portanto, indícios razoáveis de que, por mais que se queira atribuir a Hayek uma metateoria individualista, ela não pode ser definida como um individualismo ontológico, isto é, como se fosse suposto um indivíduo auto-determinado. Primeiro, porque a primazia que é conferida ao indivíduo é tão-somente uma possibilidade de ação. É claro que essa "liberdade" é reivindicada somente no nível formal (HAYEK, [1946] 1948b, p. 16). Deve-se admitir que, nesse ponto, a teoria de Hayek é vulnerável, uma vez que se preocupa essencialmente com os aspectos formais da realidade social. Mesmo assim, não se pode dizer que o autor austríaco padecia de "ilusão social",

18 "This argument does not assume that all men are equal in their natural endowments and capacities but only that no men is qualified to pass final judgment on the capacities which another possesses or is to be allowed to exercise" (HAYEK, [1946] 1948b, p. 15). E mais, a individualidade se manifesta na diferença entre a natureza e o potencial da contribuição de cada membro da sociedade. Caso contrário: "If all men were completely equal in their gifts and inclinations, we should have to treat them differently in order to achieve any sort of social organization. Fortunately, they are not equal; and it is only owing to this that the differentiation of functions need not be determined by the arbitrary decision of some organizing will but that, after creating formal equality of the rules applying in the same manner to all, we can leave each individual to find his own level. (...)There is all difference in the world between treating people equally and attempting to make them equal. While the first is the condition of a free society, the second means, as De Tocqueville described it, 'a new form of servitude'" (HAYEK, [1946] 1948b, p. 15-16).

19 Segundo Bowles (1998), pode-se encontrar em Hayek traços de preferências endógenas, isto é, como o arranjo institucional pode influenciar a formação das preferências. 
defendendo que a mera igualdade jurídica garantiria a igualdade de fato entre os indivíduos. Desde seus estudos iniciais como economista, Hayek se preocupava com os fenômenos "invisíveis" que se desenrolavam nas economias monetárias, tais como a poupança forçada. ${ }^{20}$

Por outro lado, apesar de reconhecer a existência de desigualdades políticas, ele dá pouca atenção à formação de grupos de indivíduos com o objetivo de ampliar o seu controle sobre a renda social. Ele vê essa cooperação voluntária como algo eminentemente benéfico, contanto que essa associação de indivíduos não se degenerasse em coerção sobre os outros ou que não levassem à consolidação de poderes exclusivos (HAYEK, [1946] 1948b, p. 16). Portanto, ao descon-siderar o processo de realimentação mútua entre o poder político e o poder econômico, Hayek termina por defender a liberdade jurídica formal para que o indivíduo possa buscar seus fins.

Era essa a preocupação principal do austríaco: garantir que a formulação dos fins individuais não fosse coibida de maneira explícita, pelo uso da força. Quanto mais descentralizado o poder político, maiores oportunidades estariam à disposição dos "indivíduos de gênio". Esse era o primeiro passo. Contudo, fica a pergunta: como fica o indivíduo em termos efetivos? Se, por um lado, sua liberdade jurídica lhe permite vislumbrar ganhos e benefícios advindos de seu trabalho, por outro, há uma restrição no que diz respeito ao acesso

20 Em 1928, no artigo em que discute o equilíbrio intertemporal dos planos individuais de ação, Hayek ([1928] 1994) já mostrava como a existência do crédito poderia impedir que as iniciativas individuais fossem bem-sucedidas. Em seu primeiro grande trabalho, em 1929, Hayek ([1929] 1935) investigou a fundo como o crédito gerava uma transferência "forçada" da renda dos agentes cuja remuneração era fixa para aqueles que tinham o poder de ajustar seus preços, promulgando uma distorção do sistema de preços que resultaria em desemprego e depreciação do poder de compra dos consumidores (HAYEK, [1929], 1935, p. 220). Nessa sociedade, o regime de trocas descentralizadas é disciplinado por um sistema monetário que, ao mesmo tempo em que permite o crescimento econômico (por meio do financiamento de investimentos em volume maior do que a poupança agregada disponível), impõe aos indivíduos de menor poder político (principalmente os trabalhadores, os quais não podem ajustar seus salários com a mesma rapidez que ocorrem as mudanças em seu poder de compra) uma posição social e econômica mais vulnerável. Entretanto, Hayek não enxergava aí uma desigualdade na distribuição real de poder político e econômico, mas um problema institucional. Fundamentando-se sobre o embrionário problema do conhecimento limitado dos agentes econômicos, Hayek mostrava que esse efeito re-distributivo, concentrador de renda, do crédito não era "culpa" dos bancos, uma vez que eles somente fazem o que foram solicitados (HAYEK, [1929] 1935, p. 189). Em outras palavras, as regras do sistema econômico que endossavam diretamente a expansão dos investimentos eram as responsáveis pelo problema da concentração de renda. Uma análise detalhada acerca da teoria dos ciclos e do problema da poupança forçada pode ser encontrada em Carvalho (2007, capítulos 2 e 3). 
aos recursos materiais (dinheiro) que propiciam o usufruto desses benefícios. Esse problema somente poderia ser solucionado por meio do aprimoramento das instituições sociais.

Todavia, a questão da eqüidade haveria de ficar para depois. Um risco mais urgente despontava na experiência soviética, colocando em xeque aqueles aspectos mais explícitos da organização social, tais como a liberdade jurídica e a propriedade privada. Urgiase, antes de qualquer outra coisa, defender a causa das liberdades formais. O modelo soviético implicava, para Hayek, a formulação centralizada de fins coletivos a serem seguidos pelos cidadãos; ou seja, rompia-se com o preceito da autonomia de escolha quanto aos fins individuais. Os agentes econômicos deveriam submeter-se a propósitos determinados em esferas alheias ao seu conhecimento. Hayek entendia que tal concepção havia-se infiltrado na ciência econômica por meio da teoria do equilíbrio, a qual submetia todos os propósitos individuais à obtenção de um estado de equilíbrio. Um ex-aluno de Hayek ilustra a incompatibilidade do conceito de equilíbrio (representada pelo individualismo racionalista do modelo de equilíbrio geral) com "a marcha da história", dizendo que:

Such a conception [do equilíbrio] has, perhaps, its greatest usefulness in compelling us to as, in view of its evident utter unattainability, what in fact the process of history must be like. Individuals will not necessarily surrender freedom of imagination, of enterprise, of attempted exploitation of the void of time-to-come, in order to try to reconcile their ambitions with those of all other individuals. The seething cauldron of history mocks such a notion. Even at a lesser level of generalness, the difficulties multiply. Different individuals will plan their respective courses of action in differently-defined, differently conceived spaces. A dimension which appears in one such space will be absent from others. Two men cannot arrange to walk side-by-side when each is studying a map of a different country (SHACKLE, 1990, p. 167-168).

A obtenção do equilíbrio exige, dessa forma, não somente a compatibilidade geral dos planos individuais, mas também demanda dos indivíduos uma percepção única da realidade, uma percepção objetiva. Ademais, coloca sobre os indivíduos uma responsabilidade que está muito além do que comportam as suas capacidades cognitivas. Ou seja, se os efeitos de uma ação se desdobram sobre partes do sistema que extrapolam o seu campo de influência, o indivíduo não pode antecipar a natureza dos efeitos e, por isso, fica impedido, de antemão, de se ajustar ao equilíbrio do sistema. Quando Shackle 
utiliza a expressão de dois agentes econômicos andando lado a lado, mas "estudando mapas de diferentes países", salienta a visão de Hayek acerca de individualidade do ser humano em termos de sua ordem sensorial, isto é, de suas percepções.

\section{A indeterminação do processo social e as limitações do individualismo hayekiano}

Schumpeter (1964, v. 1, p. 273) escreveu que os problemas de qualquer ciência social se dividem em dois grupos metodologicamente diferentes: "o grupo que se centra na questão de saber como o real comportamento do povo produz o fenômeno social que observamos, e o grupo que se fixa em torno do problema de saber como este comportamento chega a ser o que é". É inegável que Hayek tende a dar mais atenção ao primeiro grupo analítico, de forma a ressaltar os produtos não-intencionais dos padrões de comportamento dos grupos. Como se buscou mostrar, sua proposta se dá mais como um contraponto à idéia de uma razão humana poderosa, do que como representação positiva dos processos de realimentação e formação de padrões comportamentais. Sua abordagem limita-se a reconhecer a limitação da cognição humana frente à complexidade inescrutável do mundo real. ${ }^{21}$

21 Comentando sua contribuição à teoria dos ciclos econômicos, Hayek aponta os objetivos limitados de seus trabalhos, propósitos esses que podem ser estendidos, com o aval de Caldwell (1994, p. 312), ao assunto aqui em foco: “... o que eu fiz me parece ter sido mais apontar barreiras a um avanço na trajetória escolhida por outros do que oferecer novas idéias que abriram caminho para maiores desenvolvimentos". (HAYEK, 1977, p. 9). É nesse ponto que sua teoria evolucionária da herança cultural se mostra mais vulnerável às críticas. O problema do processo seletivo de Hayek é que ele é pouco operacionalizável. A ausência de mecanismos claros de seleção, como hereditariedade e de variação, compromete sua capacidade preditiva acerca das futuras transformações do grupo social. O método evolucionista de Hayek, de fato, peca pela indeterminância excessiva, em caso de se buscar uma definição de padrões estáveis e racionalmente antecipáveis. Fiani (2002, p. 1924) defende que o fato de o sujeito hayekiano não ter a oportunidade de refletir sobre o ambiente em que vive, antecipando os efeitos que o abandono das regras prevalecentes teriam sobre o todo social, coibiria o caráter inovador de sua atuação. Como os indivíduos geralmente reagem às circunstâncias mais imediatas e específicas do ambiente em que agem, ficaria indeterminado o processo de transformação e estabelecimento de novas regras. Tem-se, portanto, que essas reações localizadas, por meio da imitação e da disseminação, adquiririam o caráter de regularidades compondo uma verdadeira ordem geral. De Vlieghere (1994) faz a mesma crítica, apontando a ausência de uma explicação convincente quanto à possibilidade de aperfeiçoamento das instituições sociais. Ademais, Burczak (1994, p. 53-54) aponta a falha da teoria hayekiana em captar a dimensão retórica da linguagem, no sentido de criar significados que influenciam a ação dos indivíduos. Apesar de consistentes, tais críticas extrapolam os propósitos do programa de pesquisa hayekiano. 
Após a consideração dos aspectos principais da metateoria hayekiana do individualismo, é possível re-avaliar a leitura que Paulani (2005, capítulo 4) faz da contradição patente da qual Hayek buscou escapar. Nas palavras da autora, o impasse enfrentado por Hayek é o seguinte:

Hayek, o verdadeiro individualista, acaba por concluir que o indivíduo (exceção feita a seus propósitos particulares) desconhece a maior parte dos processos que freqüentemente determinam a sua ação, senão vejamos: o saber, que ele subjetivamente detém, depende fundamentalmente da linguagem, caracterizada, tanto quanto o mercado, como uma ordem espontânea e não como produto deliberado da intenção humana; as regras, que junto com tal saber fornecem os parâmetros da ação dos agentes, eles simplesmente as seguem sem se perguntarem o que significam ou porque existem. Em suma, para Hayek, o indivíduo é objeto de processos que se desenvolvem às suas costas, que dirigem da sombra o seu comportamento, e sobre o quais ele não pode ter nenhum controle individual. Onde fica então sua propalada autonomia, sua independência, sua soberania de ator-sujeito? (PAULANI, 2005, p. 106 - grifos nossos).

Como se tentou mostrar, os processos mentais pelos quais passa um único indivíduo são de uma complexidade maior do que a própria mente pode captar. $\mathrm{O}$ histórico de suas experiências, o ambiente em que vive e a sua estrutura mental (e também cerebral) engendrarão interpretações da realidade que provavelmente não serão reproduzidas de forma idêntica por outros indivíduos. É exatamente essa peculiaridade do indivíduo que, uma vez potencializada pelas instituições espontâneas e historicamente constituídas, dá ensejo à marcha da história, mesmo que a participação de cada um nesse processo não possa ser discriminada. Essa indeterminação se dá porque o fracasso da empreitada de um indivíduo pode significar a oportunidade de sucesso para outro. Mesmo assim, não se pode exigir do primeiro que saiba exatamente os efeitos sociais de seu insucesso. Por isso, Hayek entende esse processo de transformação como sendo resultado, muitas vezes, de acidentes de percurso: descobertas inusitadas que estavam à disposição de todos, mas que ninguém soube assim interpretar.

A soberania decisória do indivíduo, para Hayek, não existe. Ele deixa claro já de início que o indivíduo tem sua natureza e seu caráter determinados pela sua existência na sociedade (HAYEK, [1946] 1948 b, p. 6). Seus propósitos particulares por outro lado resultam de um intrincado e complexo processo associativo e classificatório de estímulos oriundos do mundo externo. A composição da estrutura classificatória é um processo evolucionário, fortemente determinado pelo meio social. A percepção de diferentes regularidades no mundo 
externo e das oportunidades que nascem do comportamento fundamentado em regras seguido pelos outros indivíduos dá ensejo a descobertas e inovações, as quais serão implementadas. O sucesso ou insucesso dessa empresa será resultado da avaliação social, feita via mercado. ${ }^{22}$

Os processos sociais impõem ao indivíduo, portanto, um crivo à consecução de seus objetivos. Dizer que a contribuição de cada um é "testada" e "corrigida" pela contribuição dos outros não equivale a dizer que o indivíduo é influenciado diretamente por esse processo de seleção quando da formulação de seus "propósitos particulares". É justamente por desconhecer o processo de correção em seus pormenores e em sua alteridade que o indivíduo formula seus planos de ação com relativa autonomia. ${ }^{23}$

22 O mentor maior de Hayek, Ludwig von Mises dá a medida dessa liberdade com limites: "Na economia de mercado, o indivíduo é livre para agir nos limites que lhe são impostos pela propriedade privada e pelo mercado. Suas escolhas são inapeláveis. Seus concidadãos terão de levá-las em conta ao decidirem sobre suas próprias ações. A coordenação das ações autônomas de todos os indivíduos é realizada pelo funcionamento do mercado. A sociedade não diz a uma pessoa o que fazer e o que não fazer. Não necessidade de tornar a cooperação obrigatória por meio de ordens ou proibições. A não-cooperação se penaliza a si mesma. Ajustar-se às exigências do esforço produtivo da sociedade e procurar atingir os seus próprios objetivos pessoais não são coisas conflitantes. Conseqüentemente, não há necessidade de uma agência do governo para arbitrar conflitos que não existem. O sistema pode funcionar e cumprir o seu papel, sem a interferência de uma autoridade que emita ordens e proibições e que castigue quem não as acata" (MISES, [1949] 1990, p. 716).

23 Não se trata, aqui, de atestar a favor ou contra a efetiva liberdade do indivíduo, mas tãosomente de reconhecer que, apesar da complexidade dos processos sociais dos quais o indivíduo participa e pelos quais é influenciado, sua singularidade encontra espaço para se manifestar, a saber, na sua participação espontânea no mercado, a qual se cristaliza no ato puro da ação e nos efeitos não intencionais que ele gera. Em termos mais concisos, o fato de Hayek postular a impossibilidade de se determinar a origem e o processo de constituição dos elementos que formam a percepção humana reforça a noção da singularidade do ser humano, o qual, em contato direto com outros - ou indiretos pelos efeitos que sua ação faz pesar sobre o comportamento daqueles com quem mantinha contato -, gera um estado de coisas cujos ingredientes coexistem como causa e efeito, desempenhando as duas funções simultaneamente. Esse todo que se insere no tempo é essencialmente irredutível à composição discriminada das razões individuais que o engendraram, frente à limitação cognitiva do ser humano. Não é por essa razão, contudo, que se torna possível atribuir ao indivíduo um caráter contraditório. É possível, sim, alegar que a racionalidade da qual resultam suas ações padece de uma circularidade, ou até mesmo uma tautologia, que a torna indeterminada. Mesmo assim, não se deve perder de vista que a condição para essa complexidade se encontra na singularidade mesma de cada indivíduo. É justamente por que o indivíduo age e contribui "anonimamente" com o "todo social" que sua racionalidade nele se dilui. Sua racionalidade se manifesta efetivamente pelas suas ações, mesmo que seus efeitos sobre a coletividade não sejam apreensíveis. Advogar que a definição desses propósitos, para Hayek, esteja plenamente submetida à linguagem, às regras sociais e aos efeitos da localização econômica implica retirar do argumento, à guisa de generalização, o elemento fundamental de sua análise. É o equivalente a analisar a Economia Política de Marx sem a luta de classes. Pode-se discordar da hipótese, mas supô-la ausente implica desfazer-se da teoria como um todo. 
Hayek não trata, portanto, de uma liberdade plena, sem a interferência de regras e costumes que distorçam a existência do indivíduo como corpo social. (PAULANI, 2005, p. 108). Ele desenvolve sua tese no sentido contrário, salientando uma liberdade de caráter negativo, qual seja, a ausência de coerção coletiva ou estatal direta na determinação privada dos fins almejados pelos indivíduos. Em outros termos, está em questão uma liberdade formal, expressa na igualdade jurídica que confere a cada indivíduo a possibilidade de determinar os objetivos (por mais restritos que eles sejam) de suas ações, cabendo à regras e aos costumes orientar a utilização adequada dos meios que permitirão a consecução de tais fins. ${ }^{24}$

Somente por meio desta igualdade jurídica, o indivíduo poderia colocar em funcionamento todo o potencial criador de seus dons específicos. Mesmo que o indivíduo seja um "perdido" dependendo das regras e dos costumes sociais para a sua orientação, há nesse sistema um espaço privado para a mudança que, apesar de influenciado pelas instâncias supra-individuais, não determinam o seu funcionamento. Esse espaço é representado exatamente pela individualidade, nos propósitos particulares de cada agente econômico na busca da satisfação de suas necessidades materiais privadas. Seu limitado poder dedutivo e sua restrita capacidade de acumular informações não constituem um empecilho ao sistema. Ao contrário, formam uma potencialidade: não haveria progresso se o indivíduo tivesse que se preocupar com todos os efeitos que suas ações teriam sobre o todo, cada vez que tivesse que tomar uma decisão. ${ }^{25}$

24 "Freedom from coercive interference by government or other individuals and groups is important because no one can know what is good for other persons. There are no knowable objective standards according to which one group of people could legitimately force another group of people to act. In fact, Hayek defends the freedom afforded by private property because individuals often do not even know what is good for themselves. Private property and markets free people to discover and create new technologies and preferences" (BURCZAK, 1994, p. 52 - grifos do autor).

25 "Nesse sistema o indivíduo abre mão de um sucesso garantido, tal como no equilíbrio, inserindo-se no terreno da incerteza. Mesmo assim, para Hayek, é preferível que o indivíduo responda a uma instância abstrata e incontrolável como o mercado, do que a Bureau Planejador que submete a maioria dos indivíduos às determinações de um punhado de seus semelhantes. "Como contraponto à arrogância da razão cartesiana que exibe um conhecimento pleno dos fatos e permite uma suposta inteligibilidade da sociedade, Hayek se alia a uma perspectiva epistemológica que parte da radical ignorância dos membros na great society. Com isso, procede a uma crítica a todo e qualquer cientificismo e deixa clara sua inesgotável identificação ao racionalismo crítico popperiano com suas proposições constantemente renovadas de conjeturas, sua humilde correção de erros e sua conseqüente provisoriedade do conhecimento. Deixa também claro que a ignorância, atributo até então desqualificado dos indivíduos é ironicamente sua porta de entrada para conquistar uma possível liberdade" (GANEM, 2005, p. 8). 


\section{Considerações Finais}

O presente artigo buscou relativizar a assertiva de que o indivíduo hayekiano "esboroa-se na articulação da teoria propriamente dita" (PAULANI, 2005, p. 106). O fato de os indivíduos desconhecerem a natureza efetiva de suas contribuições no complexo processo econômico, o qual extrapola a capacidade cognitiva do ser humano, não nega, senão reforça, a sua particularidade. Tal particularidade se origina na constituição própria da estrutura cérebro-mente de cada indivíduo. As regras sociais servem de apoio ao indivíduo, reduzindo o grau de incerteza da realidade e fornecendo oportunidades de mudança. A combinação entre as regras sociais e a individualidade de cada ser humano revela o papel inovador do mesmo, tão relevante no pensamento de Hayek.

Isso se dá por que, diferentemente de uma relação de determinação, as regras sociais constituem a subjetividade humana, o que implica não ser possível ponderar a influência dessas regras sobre a formação das percepções. Essa imponderabilidade dá ensejo a um potencial de transformação, o qual se aplica, por sua vez, pela conjugação das regras sociais às ferramentas próprias das faculdades humanas, possibilitando a superação de uma dada realidade objetiva com a aprovação não intencional daqueles que partilham do mesmo espaço social.

Desta feita, dois traços particulares delineiam os limites da abordagem indivíduo-sociedade apresentada por Hayek, a saber: (1) a ignorância radical ${ }^{26}$ frente à complexidade de um mundo inapreensível pelas suas acanhadas possibilidades cognitivas e (2) a garantia formal do exercício de uma liberdade negativa no escopo da propriedade privada. Por ser imperfeito em suas decisões e por não ter qualquer controle sobre os efeitos de suas ações, o indivíduo se apóia em regras sociais espontaneamente estabelecidas pelos hábitos e costumes sociais. Tais regras reduzem a variabilidade das circunstâncias, conferindo ao mundo externo uma regularidade perceptível, mesmo que não suscetível de predição acurada. Da experiência real, segundo o austríaco, emanam os critérios seletivos das regras que melhor atendem às exigências de uma determinada realidade social no sentido de ampliarem o exercício da liberdade.

Por ser eivado de auto-referências que se diluem no percurso histórico da sociabilidade, o indivíduo parece ter um lugar menos privilegiado como objeto de análise. O presente artigo buscou mostrar que esse entendimento não sobrevive a uma análise mais profunda

26 A expressão encontra-se em Kerstenetzky (1998). 
dos escritos do austríaco. O indivíduo é, para Hayek, o ator-sujeito do processo de transformação da sociedade. É na interseção, na negociação, na acomodação e no ajuste mútuo das trajetórias individuais que nasce um "todo" dotado de regularidade e de relativa harmonia. Entretanto, tal harmonia é meramente transitória a uma nova etapa de reajustamento das trajetórias individuais. Essa constante mutação da sociabilidade apenas pode ser explicada por que a peça elementar que forma a sua engrenagem é passível de aprendizado. Ao apreender a realidade externa sobre novas bases, o indivíduo reage às condições anteriormente estabelecidas, ocasionando, inconscientemente, mudanças na dinâmica da sociabilidade pelo movimento de agremiação espontânea das forças individuais dispersas, garantidas pela liberdade formal.

Nesse sentido, o individualismo metodológico de Hayek carece de um qualificativo adicional. Poder-se-ia adjetivá-lo de complexo ${ }^{27}$ ou de interativo, ${ }^{28}$ uma vez que, na abordagem hayekiana, não é possível conhecer as determinações particulares entre indivíduo e sociedade, o que desautoriza, portanto, a subjugação planejada da realidade social a fins coletivos predeterminados com base no arcabouço científico de previsão e de controle. Tais designações, todavia, não encerram a questão. Ao contrário, dizer que o individualismo metodológico de Hayek é complexo ou interativo revela de maneira contundente um dos pontos mais vulneráveis de sua teoria evolucionária da herança cultural, a saber, a afirmação de que a seleção espontânea de regras sociais, pelo critério do benefício social, conduz a uma ordem social progressivamente mais eficiente? Para tanto, é imperativo ir além da mera postulação da realização espontânea de uma ponte entre individualidade e ordem coletiva, delineando-se de maneira mais clara a relação entre os padrões de comportamento individual e a constituição da ordem social. ${ }^{29}$ Todavia, o indivíduo persiste em seu papel protagonista na constituição da ordem hayekiana, mesmo que não reconheça os efeitos de sua participação nela.

27 Agradeço à Professora Ângela Ganem (UFF) por suas considerações a esse respeito.

28 Tal acepção encontra-se em Kertenetzky (2007) e pode ser resumida pelo seguinte trecho:

"O individualismo hayekiano é interativo na medida em que busca dar conta das ações dos indivíduos como ações sociais significativas, densas em conhecimento não-articulado e rarefeitas em informação detalhada sobre o mundo social abrangente. O espaço intersubjetivo - de intenso consumo e produção de regras, de geração de coordenação, ao mesmo tempo que de oportunidade para mudança social - é trazido ao centro da análise" (KERSTENETZKY, 2007, p. 27).

29 Como Angeli (2007, p. 99) mostra, nem mesmo no seio da escola austríaca há consenso sobre essa possibilidade. 


\section{Referências Bibliográficas}

ANGELI, E. Hayek e a teoria das Instituições, 2007. 123 fls. Dissertação (Mestrado),Instituto de Economia, Universidade Estadual de Campinas, 2007.

BIRNER, J.; ZIJP, R. Hayek, co-ordination and evolution: his legacy in philosophy, politics, economics and the history of ideas. Londres: Routledge, 1994.

BURCZAK, T. A. The postmodern moments of F.A. Hayek's economics. In: Economics and Philosophy, n. 10, p. 31-58, 1994.

CALDWELL, Bruce. Hayek's transformation. In: History of Political Economy, v. 20, n. 4 , 1988, p. 513-541.

$\overline{313,1994 .}$

. Hayek's scientific subjectivism. In: Economics and Philosophy, n. 10, p. 305-

. Hayek's challenge: an intellectual biography of F.A. Hayek. Chicago: University of Chicago Press, 2005.

CARVALHO, A. R. Equilíbrio, coordenação e conhecimento: um estudo sobre a questão monetária em Hayek. 189 fls. Dissertação (Mestrado). Programa de Estudos Pós-Graduados em Economia Política - Pontifícia Universidade Católica de São Paulo, 2007.

FEIJÓ, R. Economia e filosofia na escola austríaca: Menger, Mises e Hayek. São Paulo: Nobel, 2000.

FESER, E. Hayek's solution to the mind-body problem. Disponivel em: http:// www.hayekcenter.org./friedrichhayek/feserseminar.html. Acesso em: 12/02/2007.

FIANI, R. Uma crítica dos mecanismos de variação e seleção no conceito de ordem espontânea de Hayek. In: Revista de Economia Contemporânea. Rio de Janeiro, v. 6, n. 2, p. 7-35, julho/dezembro de 2002.

GANEM, A. Regras e ordem do mercado nas visões de Adam Smith e F.A. Hayek In: Anais do XXXIII Encontro Nacional de Economia - ANPEC, Natal/RN (CD-ROM). Belo Horizonte: ANPEC, p. 1-15, 2005.

GALIPOLO, G.M.; GALA, P.; FERNANDES, D.A. Notas para a avaliação da influência de Marx em Douglass North. In: Anais do XXXIII Encontro Nacional de Economia ANPEC, Natal/RN (CD-ROOM). Belo Horizonte: ANPEC, p. 1-19, 2005.

HAYEK, F.A. Monetary theory and the trade cycle. Nova Iorque: M. Kelley Publishers, [1929] 1933.

. Prices and production. Londres: Routledge, [1931] 1935.

. Individualism and economic order. Londres: Routledge, [1948a].

. Individualism: true and false. In: Individualism and economic order. Londres: Routledge, p. 1-32, [1946] 1948b.

. Economics and knowledge. In: Individualism and economic order. Londres: Routledge, p. 33-56, [1937] 1948c.

. The sensory order: an inquiry into the foundations of theoretical psychology. Chicago: University of Chicago Press, [1952] 1976.

. Forword: On the way. In: O’DRISCOLL, G.P. Economics as a coordination problem: the contributions of Friedrich A. Hayek. Kansas City: Sheed Andrews and McMeel, 1977.

. The counter-revolution of science. 2. ed. Originalmente publicado em 1942. Indianapolis: Liberty Press, 1979. 
HUTCHISON, T.W. The politics and philosophy of economics: Marxians, Keynesians and Austrians. Oxford, 1981.

KERSTENETZKY. C. A.L. Hayek: the evolutionary and the evolutionist In: Anais ANPEC - V. I - Anais do XXVI Encontro Nacional de Economia (Vitória-ES), 1998, p. 231-243. . Individualismo interativo: um ensaio sobre o individualismo metodológico de Hayek In: Estudos Econômicos, v. 37, n. 1, p. 101-128, jan/mar, 2007.

MARX, K. Para a Crítica da Economia Política. Coleção “Os Economistas”. São Paulo: Editora Abril, 1982.

. O Capital: crítica da economia política: livro I. Tradução de Reginaldo Sant'Anna. 17. ed. Rio de Janeiro: Civilização Brasileira, 1999.

MISES, L. Von. [1949] 1990. Ação humana: um tratado de economia. Tradução de Donal Stewart Jr. Rio de Janeiro: Instituto Liberal.

O'DRISCOLL, G. Economics as a coordination problem. Kansas City: Shhed Andrews and McMeel Inc., 1977.

PAULANI, L. Modernidade e discurso econômico. São Paulo: Boitempo, 2005.

SHACKLE, G.L.S. F.A. Hayek, 1899. In: Austrian Economics: V. II - Editado por Stephen Littlechild. Hants, Inglaterra: Edward Elgar, 1990, p. 149-176.

SCHUMPETER, J. A. História da análise econômica.Volumes I, II e III. São Paulo: Fundo de Cultura, 1964.

SCREPANTI, E.; ZAMAGNI, S. An outline of the history of economic thought. Nova Iorque: Oxford: University Press, 2003.

SOROMENHO, J. E. de C. Um estudo sobre as origens da crítica de Hayek ao conceito de equilíbrio. 1994. Tese (Doutorado). Faculdade de Economia, Administração e Contabilidade da Universidade de São Paulo, 1994. 
